\title{
Preface to the special issue "Recent advances in nonlocal and non-classical continuum mechanics: in honor of Professor J. N. Reddy" on the occasion of his 75th Birthday
}

\section{Amirtham Rajagopal ${ }^{1}$}

Published online: 17 November 2020

(c) Springer-Verlag GmbH Germany, part of Springer Nature 2020

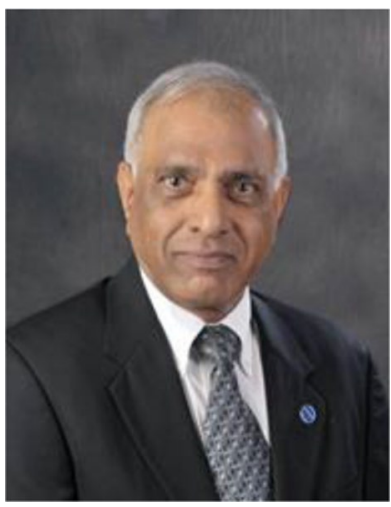

It is our great honor and true pleasure to bring out this special issue of Annals of Solid and Structural Mechanics on the occasion of the 75th birthday of our beloved colleague and outstanding mechanician, Professor J.N. Reddy. The special issue is titled "Recent Advances in Nonlocal and Non-Classical Continuum Mechanics: in honor of Professor J.N. Reddy." This special issue celebrates his numerous groundbreaking contributions to the areas of Mechanics, Applied Mathematics, and Computational Science and Engineering, especially his recent work in nonlocal non-classical continuum mechanics.

Professor Junuthula Narasimha Reddy, popularly known as J.N. Reddy in scientific community and as JN amongst his friends and colleagues (in reality, Junuthula is his family name, Narasimha is his given name, and Reddy is a social class in India; the way a person's name is written in India, like in most Asian countries, the family name comes first; when he arrived in the USA, he used the last part of his name as the last name) was born in a lower middleincome farming family in rural part of Telangana, India. As

Amirtham Rajagopal

rajagopal@ce.iith.ac.in

1 Indian Institute of Technology Hyderabad, Hyderabad, India the youngest of five children, he was the first in his family to go beyond high school. He has spent much of his times during vacation to help his father on the farm, which prepared him in later years to be a hard worker, diligent, and thorough individual. On the occasion of the 75th birthday of our beloved colleague, before we could actually summarize his accomplishments here, we present a compilation of messages and wishes received from some of his friends and colleagues on this occasion.

\section{Professor Arun Srinivasa, Texas A\&M University, USA}

"Dear Prof Reddy, your humanity, discipline, focus on advancement of knowledge, and dedication to students and their education have been an inspiration to me. Your steadfast and powerful advocacy for mechanics has greatly benefitted all people. I am honored to be counted as one of your friends and I am grateful for your continued mentorship. On the joyful occasion of your 75th birthday, I wish you many more returns of the day and hope that we continue our collaboration for many more years-I sincerely believe that the best is yet to come!".

\section{Professor Pradeep Sharma, University of Houston, USA}

"Dear J.N., I learned finite element from your book in college. Ever since, I have kept learning from your books and papers. You are an inspiration to all of us. Thanks for the wonderful mentorship you have provided to so many across the globe". 


\section{Professor Eugenio Ruocco, Department of Engineering, University of Campania “Luigi Vanvitelli", Italy}

"JN Reddy taught me many things. When I was younger, with his books he showed me the beauty of structural mechanics. With his ability to explain complexity with simplicity he introduced me to hitherto obscure concepts. Now, during our collaboration, with his example he taught me how greatness does not imply haughtiness, but the ability to listen and to communicate findings with humility and rigor."

\section{Professor Jani Romanoff, Aalto University, Finland}

"Congratulations JN on your 75th birthday. It has been a pleasure to know you in person. You are truly an inspiration in multiple dimensions. As a person, as an educator, a scientist, a mentor, a writer and most importantly as a friend. Thank you."

\section{Professor S. Gopalakrishnan, Indian Institute of Science, Bangalore, India}

"Prof. $J$ N Reddy is an outstanding academic and an accomplished teacher I have seen over the years I have been in academics. There are no words to describe his passion for research and teaching and the way he interacts with budding researchers. He has given a new meaning to the area of computational mechanics and has taken this area to multiple disciplines. I am really fortunate to have known him and interacted with him for last several years. 75 years is only a number and I am sure he will serve the academic community for a long time."

\section{Professor Ji Wang, Ningbo University, China}

"Your contribution to Science and the Growth of Engineering Mechanics Community are enjoyed and celebrated worldwide by academic and engineering colleagues for years to come.”

\section{Professor Hanchen Huang, Dean, University of North Texas College of Engineering, USA}

"As a very accomplished scholar, Professor J.N. Reddy goes above and beyond to help his students and fellow associates. Further, he is truly a down-to-earth person. I wish J.N. a very happy 75th birthday, and look forward to our continued interactions over the many years ahead."

\section{Professor Emilio Carlos Nelli Silva, University of Sao Paulo-Brazil}

"It was an honor to have met and had the opportunity to work with you both in the USA and here at University of São Paulo, Brazil. I can only thank you for your knowledge, dedication to research, good will, humility and simplicity. I hope to continue working with you."

\section{Professor Weiqiu Chen, Zhejiang University, China}

"A giant, while shaping the research areas and contributing to the society and the world, directs many others to enjoy their works and lives. Thank you JN. Happy birthday to you!"

\section{Professor M S Sivakumar, Indian Institute of Technology Madras, Chennai, India}

"We have a saying in Tamizh, "ஓருபானை சோற்றுக்கு ஒரு சோறுபகம்" (A handful is enough to know the whole). Prof. Reddy's works reflect this fact. A single book of his in the early $80 \mathrm{~s}$ on the Introduction of the Finite element method stands as a testament to this. I am sure over a million students who have thanked him for bringing out this wonderful simple to understand and implement book. He has never been tired of what he loves-the fascinating subject of Computational Mechanics where he contributes enthusiastically at the masterly levels even to this day. We are proud in celebrating his 75 th birthday and wish that we have the privilege of associating for long with him in this voyage of Computational Mechanics exploring the universe of Mechanics". 


\section{Professor Yiping Liu, South China University of Technology, China}

"Dear Prof. Reddy, it is my luck to meet you, sincerely thanks for your great support in my research these years, happy birthday, wish you and your family a brilliant birthday. "**

\section{Professor CW Lim, City University of Hon Kong, P. R. China}

"Dear JN, my very sincere appreciation goes to your mentorship throughout the years not only in research but also in sharing with me your many aspects of philosophy of life. Wishing you and your a happy 75th Birthday."

\section{Professor Carlos III, University of Madrid, Spain}

"I met Prof. Reddy many years ago. From my point of view Prof. Reddy is one of the most competent and brilliant scientific and good person I have ever found along my life. Not only their papers and books are important but his human proximity and open character should be pointed out. Many congratulations for his 75 th birthday".

\section{Professor Sami EL-BORGI, Texas A\&M University, Qatar}

"Dear Dr. Reddy, My wife and I would like to send you and your family our best wishes for health and prosperity. Happy birthday"

\section{Professor Anthony M. Waas, University of Michigan, Ann Arbor, USA}

"I am delighted to pay tribute to Prof. J.N. Reddy on the occasion of his 75th birthday. Prof. Reddy has inspired countless numbers of students and researchers in the fields of continuum mechanics, and numerical analysis of solids, fluids and heat transfer, especially composite structures. His multiple textbooks have left an indelible mark in each subject and will be used by many for several years to come. We wish him a joyful birthday and many blessings for a healthy and productive life for many years to come."

\section{Professor Armando Duarte, University of Illinois at Urbana-Champaign, USA}

"I am privileged to have met you-a great researcher and human being from whom I have learned so much. Best wishes on the occasion of your 75th birthday."

\section{Professor Srikanth Vedantam, Indian Institute of Technology Madras, Chennai, India}

"It has been my honor and pleasure interacting with Prof. J.N. Reddy over the years. His enthusiasm for teaching and love for the subject is something to learn from and imbibe into our own lives. I wish Prof. J.N. Reddy all the very best and may he continue to enthuse and inspire all of us for many years to come."

Professor Reddy received his five-year integrated Bachelor of Engineering (B.E.) degree from Osmania University, Hyderabad, India in 1968. This education has given him a broad fundamental knowledge of engineering which he could build upon in later years of his research in the areas of solid and structural mechanics, heat transfer, fluid mechanics and applied mathematics. He obtained his Master of Science (M.S.) degree from Oklahoma State University, Stillwater in 1970 and his Ph.D. (1974) degree in Engineering Mechanics from University of Alabama in Huntsville under the guidance of Professor J.T. Oden. He worked for a short period for Lockheed Missiles and Space Company in Huntsville, Alabama, before joining the University of Oklahoma as an assistant professor in 1975 . He was promoted to the rank of associate professor in 1978. In 1980 he was recruited as a full-professor in the Department of Engineering Science and Mechanics at Virginia Polytechnic Institute and State University (Virginia Tech), Blacksburg, Virginia. In 1986, he was named the inaugural holder of the Clifton C. Garvin Professorship in Engineering Science and Mechanics Department at Virginia Tech. In 1992, he was recruited in a nationwide search as the inaugural holder of the Oscar S. Wyatt Jr. Endowed Chair in the Department of Mechanical Engineering at Texas A\&M University. In 1998 he was appointed as the University Distinguished Professor (only top $2 \%$ of the university faculty hold this honor); he was named as the Regents' Professor in 2010. He held the Distinguished Nanyang Visiting Professorship at Nanyang Technological University (NTU) in Singapore (2002-2005). During 2005-2007, he served (on leave) as the first Head of the 
Engineering Science Programme at the National University of Singapore. He was the Satish Dhawan Visiting Professor at Indian Institute of Science (2012); Distinguished Visiting Fellow of the Royal Academy of Engineering (2013); Distinguished Visiting Professor, Beihang University, China and City University of Hong Kong (2014); Chair of Excellence at Universidad Carlos III de Madrid, Spain (2014-2015); Visiting Professor of the Science without Boarders Program at University of Sao Paulo, Brazil (2014-2016); and Finland Distinguished Professor (FiDiPro), Aalto University and National Technology Agency of Finland (2014-2018). He also held the Simpson Distinguished Visiting Professorship at Northwestern University (2016) and the Arthur Newell Talbot Distinguished Lectureship at University of Illinois at Urbana-Champaign (2017).

Dr. Reddy is one of the original top 100 ISI Highly Cited Researchers in Engineering around world with over 32,000 citations and h-index of 82 as per Web of Science; the number of citations is over 76,000 with h-index of 108 as per Google Scholar. Dr. Reddy serves on the editorial boards of about two-dozen journals, including Annals of Solid and Structural Mechanics, Composite Structures, International Journal for Numerical Methods in Engineering, International Journal for Numerical Methods in Biomedical Engineering, and International Journal of Non-Linear Mechanics. He is the founding Editor-in-Chief of Mechanics of Advanced Materials and Structures, International Journal of Computational Methods in Engineering Science and Mechanics, and International Journal of Structural Stability and Dynamics.

Dr. Reddy also earned numerous national and international awards and they include:

- Ralph R. Teetor Education Award, Society of Automotive Engineers (1976)

- Walter L. Huber Civil Engineering Research Prize, American Society of Civil Engineers (1984)

- Worcester Reed Warner Medal, American Society of Mechanical Engineers (1992)

- Charles Russ Richards Memorial Award, American Society of Mechanical Engineers (1995)

- Archie Higdon Distinguished Educator Award, American Society of Engineering Education (1997)

- Nathan M. Newmark Medal, American Society of Civil Engineers (1998)

- Excellence in the Field of Composites, American Society for Composites (2000)

- Belytschko Medal, US Association for Computional Mechanics (2003)

- Distinguished Research Award, American Society for Composites (2004)

- Honorary Member, American Society of Mechanical Engineers (2011)
- Raymond D. Mindlin Medal, American Society of Civil Engineers (2014)

- O.C. Zienkiewicz Award, International Association of Computational Mechanics (2014)

- Member, US National Academy of Engineering (2015)

- Foreign Fellow, Indian National Academy of Engineering (2015)

- ASME Medal, American Society of Mechanical Engineers (2016)

- Prager Medal from the Society of Engineering Science (2016)

- Foreign Fellow, Canadian Academy of Engineering (2017)

- Foreign Fellow, Brazilian National Academy of Engineering (2017)

- John von Neumann Medal, US Association for Computational Mechanics (2017)

- JS Rao Medal in Vibration Engineering, Vibration Institute of India (2017)

- JN Reddy Medal in Mechanics of Advanced Materials and Structures (2018)

- Theodore von Karman Medal, American Society of Civil Engineers (2018)

- Eugenio Beltrami Senior Scientist Prize, the International Research Center for Mathematics \& Mechanics of Complex Systems (M\&MoCS), Università dell'Aquila, Italy (2019)

- Stephan P. Timoshenko Medal, American Society of Mechanical Engineers (2019)

- Foreign Member, The Chinese Academy of Engineering (2019)

- Corresponding Member, The Royal Academy of Engineering of Spain (2019)

- Honorary Member, the European Academy of Sciences (2020)

Dr. Reddy has a very broad research background that includes applied mathematics and theoretical mechanics, with contributions to mathematics of finite elements, variational methods and principles in theoretical mechanics, and computational methods with applications to heat transfer, fluid flow, and solid and structural mechanics (and coupled phenomena). As a researcher, Dr. Reddy cares about quality than quantity though the latter exceeds the norm in his field substantially; he has published steadily from the start of his career till now, often in the best journals of his field, spanning about 45 years. For him, writing is an integral part of doing research. He takes pride in seeing his work appear in print.

Prof Reddy's pioneering works on the development of shear deformation theories (that bear his name in the literature as the Reddy third-order plate theory and the Reddy 
layer wise theory) have had a major impact and have led to new research developments and applications. This subsequently lead to the development of layer wise theory for composite that could be used to predict 3D stress fields accurately in the edge regions of composite laminates. Dr. Reddy was one of the first to work on penalty finite element models for fluid flows, including Newtonian and generalized non-Newtonian fluids. These works have been implemented into commercial software NISA (marketed by Engineering Mechanics Corporation) and HyperXtrude (marketed by Altair). The other notable work that was a new paradigm in computational mechanics, was, the development leastsquares finite elements. In recent years, Dr. Reddy has been working on three major fronts: (a) development of 7-, 8and 12-parameter shell theories and their finite elements, (b) advancement of nonlocal and non-classical continuum mechanics, and (c) pioneering the dual mesh finite domain method (DMFDM).

Another profound contribution of Professor Reddy has been in education and knowledge that impacted the educational and professional lives of scoreless young people around the world through his several text books, short courses, and workshops. Dr Reddys book on the finite element method is the most notable and classical book on FEM. Today, it is one of the most popular books on the subject. The book is also one of the first engineering textbooks to present the finite element method as a numerical technique of solving differential equations, independent of the field of application. As a result, people with no structural mechanics background were able to learn how the method could be used to solve equations arising in other fields. Dr Reddy also wrote very comprehensive books on laminated composite plates and shells and book on applied functional analysis and another one on energy principles and variational methods in applied mechanics. All of these books are now in at least their second edition.

Prof Reddy has immensely contributed to various professional activities, He has served his institution and profession admirably through Departmental, College, University, and national and international level technical committees, organizer of conferences and short courses, editor-in-chief of some major journals in his field. In particular, Dr. Reddy served as the President of US Association for Computational Mechanics, founding member of the General Council of international Association of Computational Mechanics, Secretary of Fellows of American Academy of Mechanics, member of the Board of Governors of the Society of Engineering Science, Chair of the Engineering Mechanics Executive Committee of the American Society of Civil Engineers, among others. He either served or currently serving on the editorial boards of over three-dozen professional journals. In addition, he served as the Editor-in-Chief of the Applied Mechanics Reviews, and the founding Editor-in-Chief of Mechanics of Advanced Materials and Structures, the International Journal of Computational Methods in Engineering Science and Mechanics, and the International Journal of Structural Stability and Dynamics. In addition, he organized/conducted numerous international conferences, advanced study institutes, workshops, and short courses on linear and nonlinear finite elements, composite materials and structures, continuum mechanics, and nonlocal continuum mechanics.

On a personal level, I have learned the subject of finite element method and variational principles from Professor Reddy's book in college. Since then, his books and journal papers have been a great resource for learning. Professor Reddy has been an inspiration and a role model to me. I whole heartedly thank him for the wonderful mentorship he has provided to me and to so many colleagues across the globe over the years. I wish Professor Reddy a very happy 75th birthday, good health peace and happiness in years to come and I look forward to our continued interactions over the many years ahead.

Prof Amirtham Rajagopal, Indian Institute of Technology Hyderabad.

Guest Editor, Special Issue ASSM Journal 